\title{
Design and Implementation of Adaptive Recommendation System
}

\author{
MagedElazony ${ }^{1}$, Ahmed Khalifa ${ }^{2}$, Sayed Nouh ${ }^{3}$, and Mohamed Hussein ${ }^{4}$ \\ 1,2,3,4 Systems and Computer Engineering Department, Faculty of Engineering, Al-Azhar \\ University, Cairo, Egypt \\ E-Mail: magedazony@gmail.com
}

Type of the Paper: Research Paper.

Type of Review: Peer Reviewed.

Indexed in: OpenAIRE.

DOI: http://doi.org/10.5281/zenodo.1254142.

Google Scholar Citation: $\underline{\text { IJMTS }}$

How to Cite this Paper:

Maged, Elazony., Ahmed, Khalifa., Sayed, Nouth., \& Mohamed, Hussein. (2018). Design and Implementation of Adaptive Recommendation System. International Journal of Management, Technology, and Social Sciences (IJMTS), 3(1), 101-117.

DOI: http://doi.org/10.5281/zenodo.1254142.

International Journal of Management, Technology, and Social Sciences (IJMTS)

A Refereed International Journal of Srinivas University, India.

(C) With Authors.

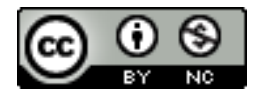

This work is licensed under a Creative Commons Attribution-Non Commercial 4.0 International License subject to proper citation to the publication source of the work.

Disclaimer: The scholarly papers as reviewed and published by the Srinivas Publications (S.P.), India are the views and opinions of their respective authors and are not the views or opinions of the SP. The SP disclaims of any harm or loss caused due to the published content to any party. 


\title{
Design and Implementation of Adaptive Recommendation System
}

\author{
MagedElazony ${ }^{1}$, Ahmed Khalifa ${ }^{2}$, Sayed Nouh ${ }^{3}$, and Mohamed Hussein ${ }^{4}$ \\ 1,2,3,4 Systems and Computer Engineering Department, Faculty of Engineering, Al-Azhar \\ University, Cairo, Egypt \\ E-Mail: magedazony@gmail.com
}

\begin{abstract}
E-learning offers advantages for E-learners by making access to learning objects at any time or place, very fast, just-in-time and relevance. However, with the rapid increase of learning objects and it is syntactically structured it will be time-consuming to find contents they really need to study.In this paper, we design and implementation of knowledge-based industrial reusable, interactive web-based training and use semantic web based e-learning to deliver learning contents to the learner in flexible, interactive, and adaptive way. The semantic and recommendation and personalized search of Learning objects is based on the comparison of the learner profile and learning objects to determine a more suitable relationship between learning objects and learner profiles. Therefore, it will advise the e-learner with most suitable learning objects using the semantic similarity.
\end{abstract}

Keywords:E-Learning, Semantic web, Adaptive learning, Recommendation.

\section{INTRODUCTION :}

E-learning and web based Training offers many advantages for E-learners by making access to learning objects and resources at any time or place, very fast, just-in-time and relevance. Elearning has offered a lot of advance in learning and training environments allowing educational community to rely on new technologies to give an improved experience and empower their learners with better materials [1].

Nowadays, in Traditional e-learning systems to offer appropriate learning content to the right learner in a correct way is a big challenge [1][2]. Nevertheless the major problem existed in current E-Learning is the amount of time spent searching for the right content, absence of personalization and there is an inadequate search technique for searching the web contents. we aims to help a user acquire knowledge at his own pace, in attractive environment and as flexible as possible by Proposing a new Elearning system based on Semantic Web.

With the fast increasing of courses and learning objects (LOs) in a diversity of media formats, it becomes quite difficult and complicated task for learners to find suitable learning objects LOs based on their priority and needs.

Semantic web-based educational systems (SWBES) represents the next generation of webbased educational systems that aim at providing several improvements on the quality of services by the use of semantic web technology.

We need to represent the knowledge in different contexts on same learning objects and adapt to different users requirements and queries. To do that, we need to add new technologies which help machines to understand these documents. These technologies are called the semantic web [3], [4]. Semantic Web can help search engines deliver better search results.

Traditional search engines cannot understand the text of the learners and his interests. because they base on a set of keywords that are inserted by the Learner for syntactic search to get the desired results with a different indicator lead to incorrect results, irrelevant or no results to all users when searching [5]. We are also faced with the need to adapt the learning process to the progress of the e-learner, his preferences, as well 
as existing competencies, to ensure that the system is both effective and efficient, especially considering the multitude of learning objects in existence.

When the learner search for learning objects Keyword-based model that is based on keywords matching leads to "too many or nothing "and Users often cannot specify appropriate and exact keywords for a valid query, there is no way the system can learn what the user means and requires by such queries. Adaptive e-learning Recommender Systems using semantic web can solve these problems and improve Traditional e-learning systems.

To do that, the user's profile ontology is compared to some reference characteristics. These characteristics may originate from the information item (the content-based approach) and the user's social environment (the collaborative filtering approach). These approaches were named a recommender system. It is also defined as information filtering, that use predefined rules to recommend the learning contents to learners and filter information.

Content filtering recommends based on the similarity between contents for one user while collaborative filtering works based on similarity between user profiles. Content filtering and collaborative filtering work based on rating system

However, collaborative filtering has a problem called "cold start", which indicates dependency on a collaborative filtering technique that relies on inadequate user information from the past. Content based filtering considers to one user, so the results are not shareable. Therefore we propose a e-learning adaptive semantic recommendation system. We use the rule filtering technique as the adaptive recommendation technique. We propose this system to help learner choose and find learning contents they want to learn. Based on semantic web technology, the ontology will be used to gather learning contents and Use of ontology for knowledge representation in knowledge-based recommender systems.

In this paper, we design and implementation of knowledge-based industrial reusable, interactive web-based training at the seaport and logistics sector and use e-learning based on semantic web system to deliver the learning contents to the learner in flexible, interactive, and adaptive way using a hybrid technique of collaborative filtering and content-based filtering to solve the problem of cold start, we propose adaptive recommendation e-learning systems which have two system. The first is used in the start of the course which recommends the effective and suitable learning contents according to his condition. The second used during the course to track learner progress and evaluate learning performance and rate, the proposed system is considered an adaptive learning model that converts the searching technique from syntactic search to semantic search.

In this approach Recommender systems have been used for e-learning environments to recommend useful materials to users based on their priority and needs. We use Pre-test and post-test to check the knowledge of the user before and after course. Pre-test determine the knowledge about the course initially. Post-test determines learning ability of users, it also compare the difference of learning performance of Learners. We find that adaptive recommendation E-learning systems using semantic web will help the e-learner to find the information and learning object easily and relatively for their queries and interest.

This research investigated the following question "Is it possible to construct an automated adaptive recommendation e-learning system learning using semantic web technology that recommend instructional content and learning objects suited to the cognitive ability and instructional preference of a E-learner, independent of domain and ensuring that no meaning is lost from adaptive strategies?”

In this paper, the knowledge base is created using the RDF framework proposed by the W3C to represent their data, ontology is used to represent knowledge about the learner and learning resources. We use the World Wide Web Consortium (W3C) recommender ontology language, web ontology language (OWL) to create ontology. 


\section{RESEARCH METHODOLOGY :}

A research approach is defined as the methodology that can be followed during the research. Our research approach mainly follows the Qualitative Analysis Approach proposed by Taylor and Renner [6].

The qualitative analysis approach attempts to put structure to qualitative data. Qualitative data collected in this paper is from top ranked Journals such as IEEE, Springer, Elsevier and ACM, Proceedings, Publications and trusted websites such as the W3C website. After data collection, we follow Taylor and Renner approach which consists of five steps. They are:

1. Understanding of data.

2. Focusing the analysis by questioning what we want to find out.

3. Categorizing information and identify ideas, concepts and terminology.

4. Identifying the relationship between different categories.

5. Explaining what new things we find and learn.

Data Collection is the methods by which data obtained include surveys, interviews, questionnaires, and case studies. In addition to literature reviews, we made face-to-face and telephone interviews with members of relevant organization's and committees in seaports and trade domain.

The research methodology in this paper was prepared in the frames of constructive method. The constructive research method in this paper takes 5 phases: (1) literature review; and (2) problem identification; (3) Theoretical framework; (4) practical implementation and (5) experiment.

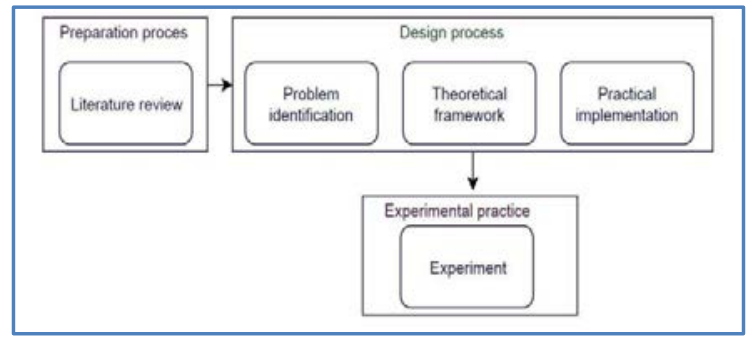

Figure 1: Constructive research method

A systematic review of related works and analytical research methods were used for revealing the advantages of the use of Semantic Web technologies for e-learning and for recommendation system in e-learning and adaptive learning and semantic search. The theoretical framework is designed to explain the e-learning systems using semantic web and the need of the new technological solutions after problem identification. Practical implementation phase evaluated during the experimental phase. Furthermore, we use e-Learning Analytics (eLA) which refers to the set of techniques aimed to extract useful information from existing online education datasets. The final goals of ELearning Analytics are to improve online education impact and student's performance and improve the return on investment (ROI) of educational initiatives, such as: Helping on marketing courses among the right target audience and reducing tutoring costs.

\section{LITERATURE REVIEWS :}

Enhancing learning objects and e-Learning Contents by Using Semantic Web Technologies opens new possibilities in lessons content enhancement. (García-González \& Emilio Labra Gayo, 2017).

In this work, we present an e-learning system based on Semantic Web technologies that allow to automatically control learners' acquired knowledge in e-learning.(Gladun \& Rogushina, 2007). E-Learning refers to learning that is delivered or enabled via electronic technology Drucker [7] has defined e-Learning as "just-intime education integrated with high velocity value chains. E-Learning also defines as the use of computer technologies (ICTs) and information and to create learning experiences [8]. It is the delivery of comprehensive, individualized, dynamic learning content in real time, aiding the development of communities of knowledge, linking learners and practitioners with experts”. E-Learning aims at replacing oldfashioned time/place/content/ predetermined learning with a just-in time/ at workplace/customized /on-demand process of learning [9] [10]. An e-learning system can be defined as a social and information technological system that supports learning 
processes [11]. E-learning is also called Webbased learning, online learning, distributed learning, computer-assisted instruction, or Internet-based learning [12][13].

Web-based e-learning systems are usually used by a wide variety of e-learners with different background, skills, learning styles and preferences. E-learning is extremely beneficial in providing cost effective education irrespective of geographical boundaries and time [14][15][16].

Web-based courses and E-learning offers advantages for users and learner. By making access to learning objects and resources just-in time, very fast, and relevance, at any place or time. Traditional e-learning systems have several following problems:

- The amount of time spent searching for the right contents.

- Learning can take place at any place and time and. However, with the increase of learning contents on the web, it is a time-consuming effort for learners to access desired and suitable contents. Therefore, Traditional elearning systems do not provide flexible content delivery.

- Absence of personalization in traditional elearning systems, learners with the same plan have the same content lists for learning, even though they have different previous knowledge about their plans.

- There is an inadequate search technique for searching the learning objects. It is difficult to find appropriate web service on user's request with the absence of semanticists.

E-Learning is classified into formal and informal learning [17] :

1- Formal learning is a highly structured planned learning that obtained from activities within a structured learning setting. The teacher pushes Information he wants to the learners. Formal learning includes learning offers from schools or universities and it is delivered by teachers in a systematic planned mode.

2- Informal learning is referred to as learning by experience in which learning can be obtained through daily life activities related to work, family or leisure. In informal learning, learners make their own choices both about what they want to learn and what and techniques they will use to support the learning process. Recently, it is estimated that $20 \%$ of learner knowledge is obtained throughout formal learning and $80 \%$ is obtained throughout informal learning [18], [17].

In this paper we propose a solution to overcome the traditional e- learning problems and apply it on formal and informal e-learning and training in seaports domain which will in turn help to ensure the support of implement single window and trade facilitation.

It is important to apply a mechanism for ELS in a way that the information and resources can be accessed, sharing and reused. Semantic web technology is used to improve e-learning systems, in order to share, reuse the information easily, flexibly, and in a personalized way [22]. But With the absence of semantic, there is difficulty of resources sharing and searching, which is mostly caused by the weak-semantic learning resources and the poor sharing mechanism.

The World Wide Web was not built for machine consuming. It built for human consuming. Although everything on the Web is not Machine-understandable, its machine-readable [19], [20]. That would enable web-based applications to interact both on the syntactic and semantic level. E-learning systems using semantic web will help the earner and lecturer to find the information and learning object easily and relatively for their queries and interest [21]. The learning modules need to consist of suitable learning content modules called learning objects (LOs) which are then included in the learning activity structure. In general, courses in Learning Management Systems LMSs consist of set of Learning Objects LOs. The IEEE LTSC has developed a learning object metadata (LOM) standard known as the IEEE LOM While many definitions abound the IEEE LOM draft standard [22] defines a learning object as "any entity, non-digital or digital, that may be used for learning, education or training" LO can be defined as a digital and reusable piece of content used to achieve a learning objective. LO can be 
an audio file, a text document, a picture, a video, or a complete website. Commonly, LMSs are considered as one-size-fits-all systems as they deliver the same kind of course structure and LOs to each learner [23]. However, each Elearner has different characteristics such as levels of expertise, prior knowledge, learning styles, cognitive abilities and interests, and therefore, a one-size-fits-all systems do not support most learners in the e-learning environment, learners find it difficult to select the learning activities that best meet their criteria [24].

The Semantic Web was introduced by Tim Berners- Lee who invented the traditional World Wide Web [25] [26]. Berners-Lee, Hendler and Lassila (2001) define the Semantic Web, as "an extension of the current web, not a separate Web, in which information is given well-defined meaning, better enabling computers and people to work in cooperation", also known as Web 3.0 [27]. The term "Semantic Web" involves efforts to build a new World Wide Web architecture that enhances content with formal semantics, means the content is made suitable for machine only. One of the great promises of the Semantic Web is flexibility in accessing and identifying information [28].

The Semantic Web is considered as an evolution to WWW which aims to make all the application data and information on the internet universally machine process able and shared a in a very efficient way. It is an intelligent web which machine can understand the information semantics and services on the Internet by applying technologies and enabling inference rules to increase users' satisfaction while searching the web content [29], [30]. Motivations for inventing the Semantic Web are the limitations of the traditional Web [31]. Semantic Web provides solutions for these drawbacks by offering more efficient technologies such as XML, RDF and Ontology [32]. The main task of the Semantic Web is "Expressing meaning". In order to achieve that objective several layers of representational structures are needed [26]. The semantic web architecture can be divided into 3 parts which are [33], [34].
1. Knowledge representation is the first part consists of (XML, XML schema and RDF, RDF schema layers).

2. Ontology (Ontology vocabulary layer).

3. Agents (Logic, Proof, Trust layers).

The Semantic Web can be used for implementing an E-learning system, because it provides all means for E-learning: ontology development, ontology-based annotation of learning materials, their composition in learning courses and active delivery of the learning materials through E-learning portals [35].

We use Semantic web to Follows the structured way for keeping the information.

* Makes possible information to share \& reuse.

* Enables a web talking to machines.

* Uses certain techniques like Ontology, RDF's, XML\& SPARQL.

The Semantic Web publishing in languages designed for data such as: Extensible Mark-up Language (XML), (RDF) Resource Description Framework Web Ontology Language (OWL), and In contrast with the simple HTML, the XML allows content creators to label information in a meaningful way [25]. But the machine still knows nothing about what is meant by this structure. The Resource Description Framework then comes to represent the relationships between the data items and give more meaning for the XML labels. The Web Ontology Language OWL provides the meaning or semantics for the data syntax and solves some problems occurred such as "two databases may use different identifiers for the same concept" [25]. Then the machine needs Web Ontology Language to discover the data which have the same meaning. These technologies enable the data to be represented in a machine readable structure and hence enable the machine applying inference rules on the data to obtain meaningful results to improve the search process. The success of the Semantic Web is based on the easy creation, use and integration of semantic data [36], [37]. Briefly, the Semantic Web technology is supposed to make data located anywhere on the Web accessible and understandable, both by machines and people. 


\section{RECOMMENDATION SYSTEM :}

In the effective learning the essential elements are control of students' feedback between students and their tutor and his skills [9]. The main idea behind the proposed approach presented in this paper is that the domain ontology is not only useful as a learning instrument but it can also employed to assess learners' skills. For it, the analysis of students' mistakes allows to propose them personalized and adaptive recommendations and to improve the course materials in general. In this work, we present a Semantic Web technologies that allows to automatically control students' acquired knowledge in e-learning frame works :

\section{Adaptive e-Learning}

The Recommender systems also known as information filtering systems that assist users in products, contents, or services (such as books, web sites, movies, digital products, song, travel destinations, and e-learning material) by implicitly or explicitly collecting and analyzing preferences from other users finding [38].

Recommender systems used for e-learning environments to recommend useful materials and learning objects to the learners based on their priority and needs [39].

Adaptive e-Learning is set of techniques oriented to offer E-learner a unique and personal experience, with the final goal of maximizing their performance.

Adaptive e-Learning is based on the principle that every E-learner (in our case employee or customers of seaport domain) is unique and has a different background, learning needs, learning style, etc.

Recommender systems open new opportunities of retrieving personalized information [40]. The objective of our Adaptive e-Learning system is being able to capture those differences and translate them into contents and training processes which are relevant for each and every individual student, based on comparison of the learner profile ontology and learning object to determine a more suitable relationship between learning objects and learning profiles. Thus, it may recommend e-learner with most suitable learning objects LOs using the semantic similarity.
To support personalization, a recommender system is used to assist learners in finding the appropriate LOs which will be needed for their learning. Personalization involves the following key stages they include choosing an appropriate learning approach, depending on the learning style and approach for choosing the suitable content, in turn these contents need to devise the appropriate teaching activities suitable for that elearner.

\subsection{The Architecture}

The architecture of Adaptive recommendation eLearning System using semantic web has the following building blocks as shown in figure 2 :

- E-Learner model: Contains information about the preferences, knowledge, learning style, capabilities, etc. of each student.

\section{- Learning Objects -Knowledge} domain: Contains the set of knowledge and learning objects that need to be transmitted and taught to e-learner.

- Recommendation model: Represents the intelligence making recommendation decisions about which learning object, content elements, exercises, materials, etc. are presented to the student in order for him to acquire the knowledge contained within the knowledge domain. The Recommendation model bridges the gap between the knowledge and the student.

- E-learner interface: Allows for the learners interact with the system and presents whatever contents have been selected by the recommendation model.

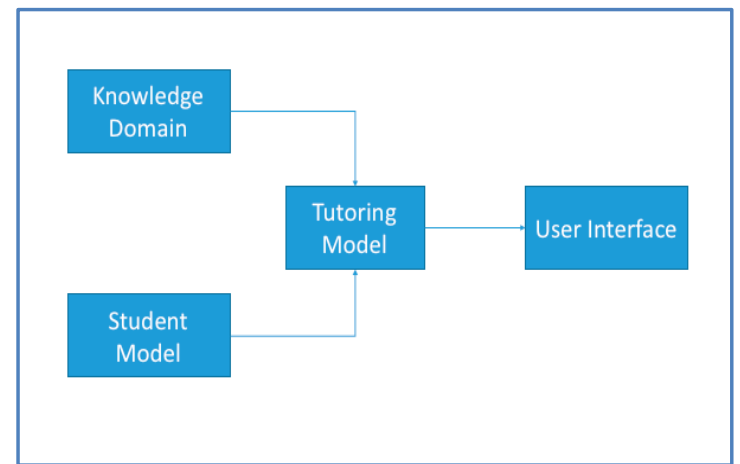

Figure 2: Adaptive e-Learning Architecture

- How to represent the knowledge in a way it can be presented in an adaptive fashion? 
- Which variables define and represent a learner and allow performing adequate recommendation decisions?

- How are recommendation decisions made? There are two main possibilities to do with their adaptive recommendation model, and the technology behind:

- Rule based systems, its create conditional pathways through the learning contents of a given course, based on intermediate check points where e-learner show their knowledge level on a set of topics.

- Recommendation based systems, use machine learning techniques to infer the different existing user profiles and the learning pathway, provide recommendations to e-learner with learning object based on their learning profiles, Choosing an appropriate learning approach, Choosing content depending on the style of the learner

adaptive recommendation e-Learning capable of providing a customized online learning experience, making this experience relevant for the e-learner and helping him to achieve higher success rates [41] [42] .

The purpose of proposed e-learning content Recommender Systems is to help trainer in port community to find not just Learning object $\mathrm{LO}$ but also the type of LO that they should appreciate from a lot of LO content and types.

Adaptive learning systems attempt to adapt learning content to suit the needs of the learners using the system. ARELS can dynamically change to better suit the learning in response to information collected during the running of the course of learning rather than on the basis of preexisting information such as a learner's gender, age, or achievement test score.

- Identify the interest, needs, media to learn i.e. audio, video, PDF and other, knowledge level, background, profile, search history of the e-learner before delivering the e-learning resource results to e- learner.

- Exactly identifies the actual requirements of e-learner and produce only such relevant learning resources to e-learner.

- The important thing is in this approach is that identifying, discovering, categorizing and presenting the relevant results to e- learner is performed by the machines, not the human.

This approach use ontology to represent knowledge about the learner and learning resources. The designed ontology will be in OWL (Ontology Web Language). We propose this system to help learner choose and find learning contents they want to learn. Based on semantic web technology, use of ontology for knowledge representation in knowledge-based recommender systems, using semantic similarity between user query and learning object create the knowledge base using the RDF framework proposed by the W3C to represent their data, use the World Wide Web Consortium (W3C) recommender ontology language, web ontology language (OWL) to create ontology, providing adaptive, personalized recommendation for each learner, ontologies in our system are developed by protégé ontology editor.

The Domain Ontology - The main reason for ontology is to enable communication between computer systems in a way that is independent of the individual system technologies, information architectures and application domain. Ontology includes rich relationships between terms and each specific knowledge domain and organization will structure its own ontology which will be organized into mapped ontology.

The domain of our learning content and the ontology we have developed within proposed system is that of Seaports. It is used mainly to index the relevant learning objects and to facilitate semantic search and re-usability of learning objects.

In the proposed model, personalized search of learning objects in e-learning is basedon a comparison of the learner profile and the learning object description [43][44]. This approach needs to present both the learner profile and the learning object description as certain data structures, it requires the development of ontological models of the learner and learning object[45][46].[24].

The semantic and personalized search of the learning content is based on comparison of the learner profile and learning object to determine a 
more suitable relationship between learning objects and learner profiles.

\subsection{Methodology for ontology development}

Firstly, we gathered detailed information of the domain from various sources, setting of classes and subclasses and Identification for the ontology to be developed is done, at second stage. Identification and setting of object and data properties between classes and subclasses is done at third stage whereas their domain and range is set. At fourth stage, Comments for domain explanation are added to the classes and properties. The fifth stage is creation of class instances and setting their properties (both data and object). In Sixth stage, consistency check is performed for which various inbuilt reasoners like HermiT can be used. Save the ontology in $\mathrm{RDF} / \mathrm{OWL}$ format at Seventh stage. In the last, ontology is exported in $\mathrm{RDF} / \mathrm{OWL}$ format for execution of queries at the desired user interface. Finally, the prototype ontology is developed for seaport domain and e-learner model.

To construct our ontology, we have adopted the seven-steps approach that is proposed by Noy and McGuinness [47], [48] as follows:

Step 1: Define The domain definition and the domain scope.

- The covered domain by our ontology is the seaports and e-learner and Learning object domain.

-The ontology will be used by E-learners, users, and domain experts via an interface.

-The ontology maintenance ensured by seaports domain experts.

Step 2 : Considering the possibility of sharing and reusing the existing ontologies, we can extract concepts from other ontologies according to our needs In order to enrich our ontology.

Step 3 : Enumerate the important keywords of the Ontology.

Step 4 : Define classes and their hierarchy. In this step, we use the ontology model that we have developed to classify the collected keywords from the previous steps according to the following attributes: Author, Title, Description, Publisher, Date, Type, Topics, Language and Keywords.

Step 5-Step 6 : Define the classes' properties and their facets. The classes' properties and their facets are defined in the designed ontology model level. Each concept in our ontology gets the model class properties which it belongs to. Last step : Create the instances: Our ontology concepts represent classes related to the elearning domain.

Figure 2 show the facility of protégé that shows the visual representation of the different classes created under the proposed e-learner model.

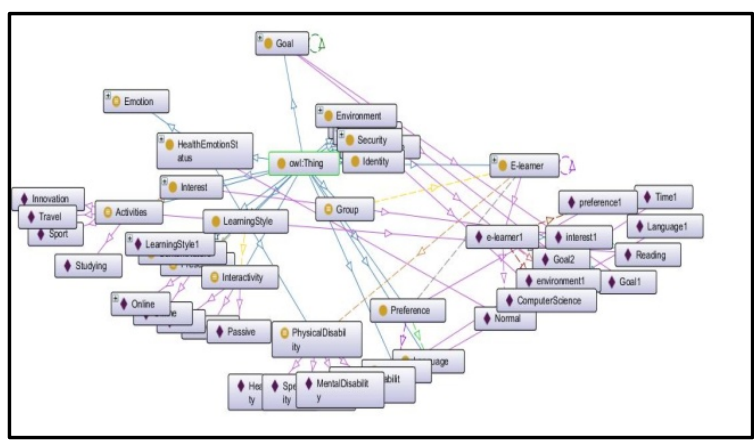

Figure 2 :E-learner ontology Model using Protege

5. CASE STUDY-DESIGN AND IMPLEMENTATION OF KNOWLEDGE BASE INDUSTRIAL ADAPTIVE RECOMMENDER E-LEARNING SYSTEM USING SEMANTIC WEB FOR SEAPORTS :

The Semantic Web technology is used as a backbone for E-Learning. Foremost, the objective is to ease efficient access to information. But, in general, a Semantic Webbased learning process could be a personalized (user customized), relevant (problemdependent), and an active (context-sensitive [49]. The previous related works which employed adaptive recommendation e-learning using semantic web in their system used various techniques for recommendation. The commonly used techniques among them are collaborative filtering. Collaborative filtering recommend learning contents to users based on similarity between user profiles. In this approach getting real rating for course material is difficult. The quality of recommendation in these systems depends on these rating. In addition this technique has problem called "cold start". Therefore this approach is not suitable for making precise recommender for e-learning 
activities. Hence, we propose rule filtering as recommendation technique Rule filtering applies as predefined rules and rules are more accurate than ranking.

We will describe the general model of solution in this section in details to understand how smart Search model recommend and retrieve the learning object.

\section{Learning objects Search: the proposed Model}

The Learning objects Search model is an example of semantic search engine based on semantic agent. The proposed model will effectively help users to find correct LO based on the semantic query. Which are implicitly and seamlessly injected into both user query and LO Search concepts stored in RDF, contrast with conventional query which depends on keywords only, and not their meanings. The LO Search model is composed of two tiers, with each tier is responsible for specific task. The tier may be composed of multiple components. The Two tiers are structured as follow as shown in Figure 3:

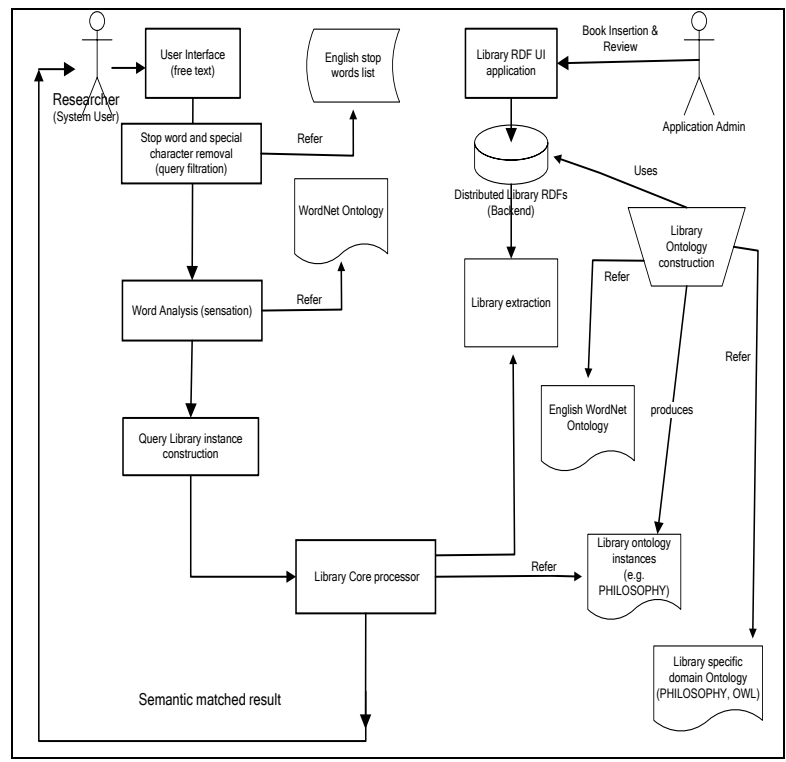

Figure 3: Semantic E-learning Architecture details

\section{The presentation tier}

This tier is the top most level of the application. The presentation tier displays information related to LO search query and answers. The presentation tier is contacted with the other tiers by outputting the results to the browser/client tier and all other tiers in the network. The Presentation layer has been implemented using J2EE technologies such as RPC, GWT and CSS.

\section{The business logic tier}

This tier controls the functionality of the application by performing detailed processing, handling transformation of input text, information exchange between the RDF data, the knowledge base (ontology) and the user interface. It Consisting of A group of agents that interact together to achieve a specific complete task related to a specific seaport Training LO Search domain. This tier is divided into four components which described in the following sections.

\section{1-The stop words removal component (query filtration)}

When the user enters her /his query in the text area, he may enter other special characters such as punctuation marks. This component is responsible for filtration of all special character and punctuation marks. Furthermore, the query words are separated by Stop words like: with, if, on, from or the Stop words are words which are filtered out prior to query processing. These words are eliminated by referring to a list contains stop words. The cause for eliminating this stop words is that these words do not add any important information and are not indexed.

\section{2-The word analysis component}

The word analysis component is the first semantic component that lists the words in the user query and fetches their references or different meanings, by referring to predefined Word Net ontology for seaport domain and learning objects terms and axioms used in any search domain. In this case we use seaport domain ontology.

\section{Heterogeneity}

The data can then be presented differently from one system to another, this heterogeneity involves communication and each business or system may designate an entity according to its local area, these naming conflicts can be homonyms conflicts, synonyms conflicts or polysemy conflicts.

Synonyms conflict: different words expressing the same information, for example, the word « 
lift» (American English) and « elevator» (British English) are two different words referring to the same information.

Another example in seaport community domain the word "Car» and " Land carrier " and « Truck» and « vehicle » are different words referring to the same information.

Homonyms conflict: same word different origin with the same pronunciation that have different meaning, eg. if two different systems exchange data, while the data exchanged is " left ", the probable conflict is presented in a sentence «left "can refer to the past of the verb « leave » or the opposite of « right ».

Another example in seaport community the word " charge - discharge» if it used in port operation its refer to charge and discharge of cargo and containers from and to the ships but if it used by another filed like electric its refer to Electric charge and discharge

Polysemy conflict: The same word of the same origin changes meaning depending on context. For example the word " Get » can be used as " we get money " in this sense the word "Get " means the amount obtained, whereas if we use " we get it » in this case the term " get » means to understand.

In this component, e- learners will be processed semantically to get proper recommendations of LOs It consists of the following steps :-

Step 1: The e-learner searching for LOs by expresses his need using his own words to form a request (query).

Step 2: The query is analyzed to check the syntax in order to make sure that the query is well formed

Step 3: First it tries to disambiguate word sense by using one of classification algorithms.

Step 4: If single definition is found, then, it processes this definition otherwise it pops up a window proposing the word meaning to the user, with the facility to let the user select another meaning.

Different word-sense disambiguation (WSD)

WSD algorithms can be plugged there :

\section{Knowledge retrieval:}

Input query is annotated according to user profile and interest then by using ontology semantically relevant information is retrieved. Semantic web is used to make the-learning system more responsive and interactive.

\section{Ontology enrichment tool}

The proposed Adaptive Recommendation Elearning using semantic web (ARELS) system provides an ontology enrichment tool in which it enriches the ontology with new concepts from the list of the concepts that are requested by the learner but not included in the domain ontology, the system provide system administrator with a tool they can use it to edit existing ontology and add new concepts.

In this component, E-learners needs will be processed semantically to get proper recommendations of LOs.

\section{The Query Library instance construction component}

As the query is normalized, another component begins the work of constructing anonymous domain instance that represents this query in order to be matched against stored LO names instance in knowledge base (RDFs). This component is responsible for this task.

\section{The Library core processor component}

This is the most important component in the model, which performs multiple operations. Including Learning Objects preparation, RDF indexation, instance ontology matching, Library ontology instance references, preparing the matched result to be sent to e-learner and finally sorts the result according to their interested data field as shown in figure 4 .

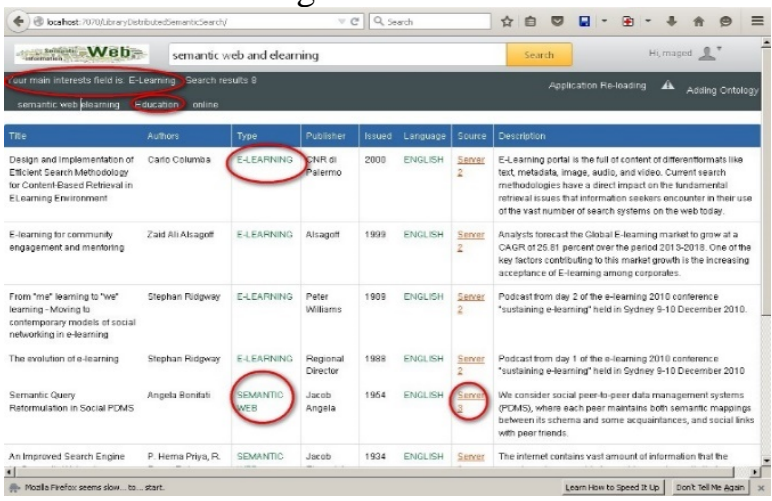

Figure 4 - Sample answer to the user query, with E-learning as main interested filed Personnel knowledge search engine personalize knowledge according to e-learner profile and support to search learning objects suitable for 
user,The Trainer of web-based e-learning training systems in seaports domain belong to different categories based on their skills, background, preferences and learning styles and job filed. We focuses on personalized semantic search and recommending learning content material and type that are appropriate to the learning environment.

\section{Developed System Feature:}

The features of the developed system include:Personalized Content Recommendations: The learning process takes into account the user's preferences and personal needs, i.e., the user has to explicitly specify these preferences or that the system has the ability to infer them through a monitoring process. Adaptive learning content, maximize students' performance and increase motivation by considering that every student has different knowledge, educational needs and learning style.

Adaptively: The user's preferences change over time and the system track them and properly adjust to them. The whole history of the elearner learning behaviour taken into consideration, and not just the user's recent actions.

Extensibility: the E-learning system is extensible in terms of the learning material and learning objects it provides. It's easy for the system to incorporate new courses and learning resources.

Inter-operability: E-learning system able to both access content from and provide content to digital libraries and other e-learning systems (Semantic Web Semantic Integration of heterogeneous data sources).

\section{RESULT AND DISCUSSION :}

E-learning and Web-based courses offer obvious advantages for Trainer by making access to Training resource just-in-time, very fast, and relevance, at any time or place, we present an approach for design and implement a Semantic e-learning system, which focus on the RDF data model and OWL ontology language. We demonstrate the effectiveness of this approach through several experiments using different type of courses taught in Damietta port at Egypt.

The semantic and personalized search of the learning content is based on comparison of the learner profile and learning object to determine a more suitable relationship between learning objects and learning profiles. So, it will advise and recommend e-learners with most suitable learning objects using the semantic similarity to retrieve semantic matched learning objects.

We propose this system to help learner choose and find learning contents they want to learn. Based on semantic web technology, the ontology will be used to gather learning contents and Use of ontology for knowledge representation in knowledge-based recommender systems, the knowledge base is created using the RDF framework proposed by the W3C to represent their data and ontology is used to represent knowledge about the learner and learning resources.

Ontologies in our system is developed by protégé ontology editor. The aim of this research is to improve the learning experience and learning outcomes via Design and Implementation of knowledge Base Industrial Adaptive Recommender E-Learning System Using Semantic Web.

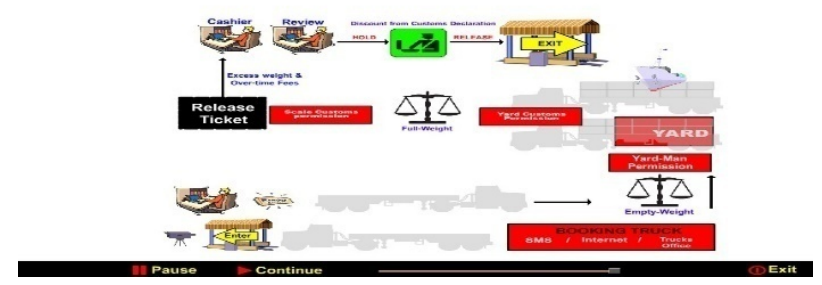

Figure 5 : Port training system.

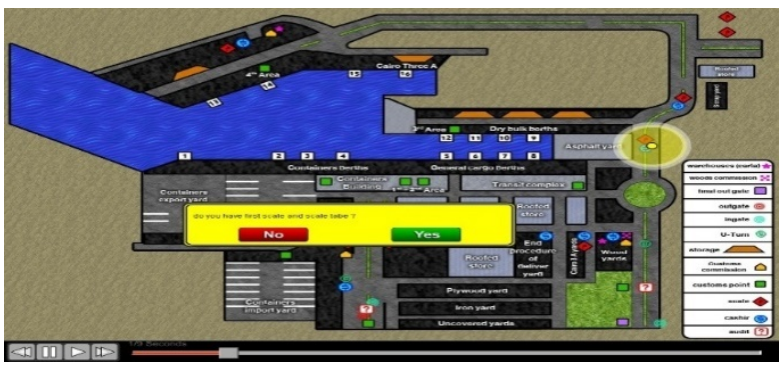

Figure 6 : The Whole Virtual World with

Channels, Terminal, gates, berth and Roads.

Figure 5 and 6 show the Web based training system. The interface is provided by a web browser, where port training system is embedded into a HTML page. The symbols in 
the right corner of the screen tell where the Channels, Terminal, gates (in /out), berth, Scales, warehouses, Customs and Roads located in real system. In figure 7; a histogram reports the average Trucks waiting times in Damietta port to complete its work Cycle .Table1 shows the time taken (in minutes) to complete trucks cycle. As shown in figure 7 the Trucks Cycle Time is reduced from $150 \mathrm{~min}$ to $50 \mathrm{~min}$ after implementation of the Training Simulator in Damietta port at Egypt. From Table 1, it can be observed that the use of training has significant impact on the number of hours spent waiting by trucks in Damietta port at Egypt to complete its cycle in customs. The users now have a good knowledge about what he must do to complete the truck cycle because we use adaptive recommendation e-learning system using semantic web to trainee and teach the employee and customers the automated work cycles and the formal rules about every step in work cycle spatially trucks cycles.

Table 1 : Trucks waiting time at the customs in 2016 at Damietta port

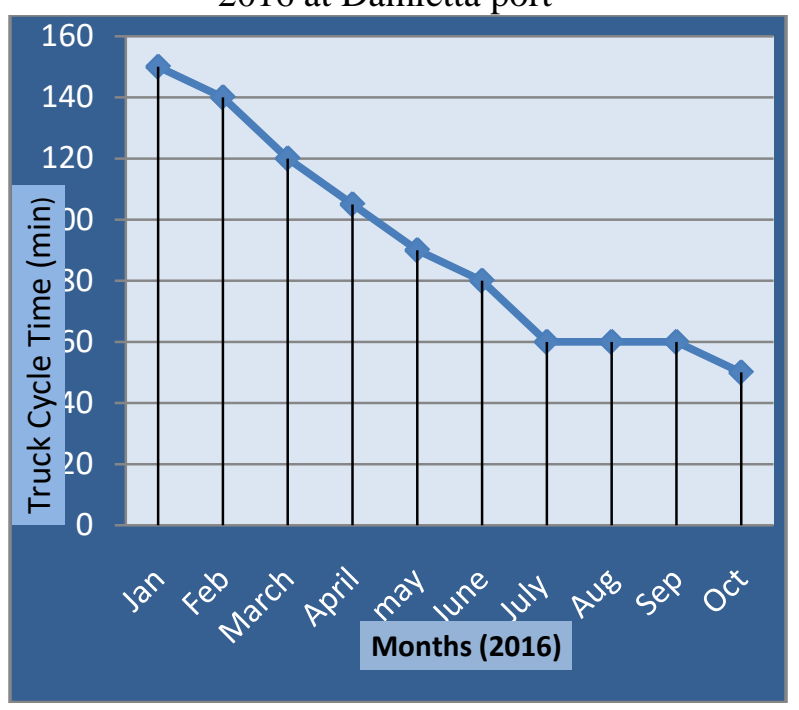

Number of trainees who are trained on our Training Simulator is 60 employees and customers, in the period from January 1, 2016 to January 31, 2016;

Here we compare between three systems:

There is no training for users (no system). The users dealing with the system in the port but with no knowledge about the automated system. $\mathrm{N}=13.4$.
Using e-learning to teach the users how to deal with the automated system in the port (old system), but we don't use adaptive recommendation or e-learning using semantic web. $\mathrm{N}=8.7$.

Using adaptive recommendation e-learning system using semantic web, to deliver the learning objects to the learners in flexible, an interactive, and adaptive and flexible manner. $\mathrm{N}=5.7$.

From Figure 7 and Table 2, it can be observed that the use of current training simulator has significant impact on the number of hours spent waiting by trucks in Damietta port at Egypt to complete its full cycle compared with other systems. The truck dual time is reduced from 13.4 to 5.7 .

Table 2 : waiting time for trucks before using simulator in training and after. For full truck Cycle in Damietta port.

\begin{tabular}{|l|l|l|l|}
\hline Systems & $\begin{array}{l}\text { no } \\
\text { system }\end{array}$ & $\begin{array}{l}\text { Old } \\
\text { system }\end{array}$ & $\begin{array}{l}\text { Current } \\
\text { system }\end{array}$ \\
\hline $\begin{array}{l}\text { The mean } \\
\text { waiting } \\
\text { time(hour) }\end{array}$ & 13.4 & 8.7 & 5.7 \\
\hline
\end{tabular}

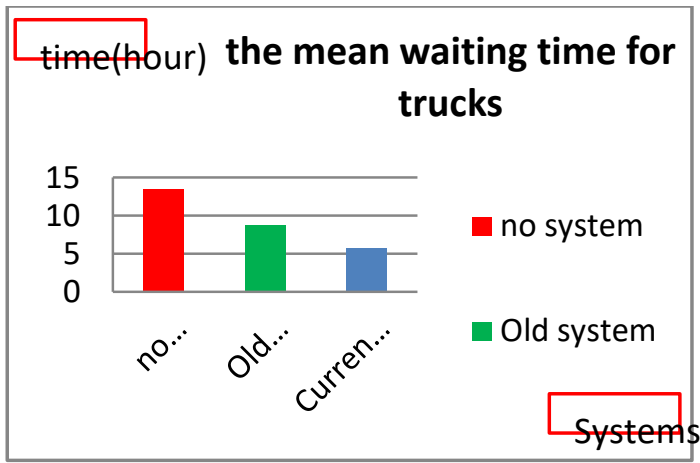

Figure 7: The waiting time of Trucks in Damietta port.

\section{The main benefits of the system is :-}

(1) Maximize e-learners learning performance.

(2) Improve the quality and effectiveness of learning objects.

(3) Proactively act on ongoing learning processes and mitigate upcoming risks.

(4) Understand the e-learner educational needs.

(5) Capitalize the LMS investment and ROI while adding adaptive capabilities to the courses. 


\section{CONCLUSION :}

This paper proposed a design and implementation of knowledge-based industrial reusable, interactive e-learning and web-based training system using semantic web. The proposed work is applied in seaport and logistics sector for trade facilitation and single window implementation and use e-learning based on semantic web system to deliver the learning contents to the learner in flexible, interactive, and adaptive way using a hybrid technique of collaborative filtering and content-based filtering to solve the problem of cold start, The architecture presented in this paper is considered an adaptation model that improve the search by converts from syntactic search to semantic search. The recommendation and personalized using semantic search of the learning content is based on comparison of the learner profile (ontology) and learning object (ontology) to determine a more suitable relationship between learning objects and learner profiles. Thus, it may advise the learner with most suitable learning objects using the semantic similarity. The proposed research work solves the limitation of current traditional e-learning environment by providing most relevant learning resources to e-learner quickly. We have developed a Semantic Web-based e-learning system, which focuses on OWL ontology language and the RDF data model. The purpose e-learning content Recommender Systems is to help trainer in port community to find not just Learning object LO but also the type of LO that they should appreciate from a lot of LO content and types according to the requirement of the learner, the ontology will be used to gather learning contents and Use of ontology for knowledge representation in knowledge-based recommender systems, The knowledge base is created using the RDF framework proposed by the W3C to represent their data and ontology is used to represent knowledge about the learner and learning resources.

We improve courses Search for E-learning Content Management System based on Semantic web technologies such as Resource Description Framework (RDF), RDF Schema (RDFS), Web Ontology Language (OWL), Uniform Resource
Identifier (URI), XML, and SPARQ.

We use the semantic web to improve e-learning and courses Search by using adaptive recommendation system. The main purpose of our paper was to provide flexible and personalized adaptive access to the learning materials. The main contribution is our model for Improve information retrieval and e-learning system using semantic web technology, The Used Technologies are introduced this paper significantly contributes to the limited literature on adaptive recommendation e-learning using the semantic web.

We implement the adaptive recommendation system using the state-of-the-art technologies and new trends in e-learning and Semantic Web such as such as (Knowledge representationKnowledge acquisition- ontological engineering -Ontology Sharing and Reuse- Semantic Web Semantic Integration of heterogeneous data sources- Solutions for bridging the gap between Web of Data and the Web of Services).

The experiment's results find that the use of semantic web and adaptive recommendation the subject ontology extension approach satisfyingly contributes to an improvement in the accuracy of learning objects recommendation.

In the future, we may make improvements the keyword clustering algorithm through identifying synonyms among keywords. Furthermore, we expect to develop reference ontology using agent system and then assess the impact of agents on the adaptive recommendation system.

\section{REFERENCES :}

[1] G. Fischer, "User Modeling in HumanComputer Interaction," User Modeling and User-Adapted Interaction, pp. 65-86, 2001.

[2] Wei and Min, "Research of Ontology-based Adaptive Learning System," iscid International Symposium on Computational Intelligence and Design,, pp. 366-370, 2008.

[3] J. Heflin, "Toward the Semantic Web: Knowledge Representation in A dynamic, Distributed Environment," Ph.D. Thesis, University of Maryland, College Park, 
2001.

[4] S. Decker, S. Melnik, F. Harmelen and D. Fensel, "The Semantic Web: The Roles of XML and RDF," IEEE internet computing, vol. 4, no. 5, p. 63, 2000.

[5] D. F, H. Ian, V. Frank, M. Deborah and F. Peter, "OIL: Ontology Infrastructure to Enable the Semantic Web," IEEE Intelligent Systems, vol. 16, no. 2, 2001.

[6] E. Taylor-Powell and R. Marcus , , Analyzing Qualitative Data. Program Development and Evaluation, Madison, Wisconsin: University of Wisconsin, Extension, 2003.

[7] P. Drucker, "Need to Know Integrating eLearning with High Velocity Value Chains,” A Delphi Group White, 2000.

[8] W. Horton, E-learning by Design, Pfeiffer, 2006.

[9] L. Stojanovic, S. Steffen and S. Rudi, "eLearning based on the Semantic Web," in WebNet'2001 World Conference of the WWW and Internet. AACE (2001), 2001.

[10] N. Kontodimopoulos, A. BOUKOUVALAS1, K. Savidakis and A. Gasparinatou, "Distance-Learning Educational Material in the Biomedical Engineering Degree Program,” in WSEAS Int. Conf. on ENGINEERING EDUCATION, Venice, Italy, 2004.

[11] Hoppe, G.; Breitner, M. H, "Business Models for E-Learning," in Elearning,models,istrument,experiences, of the Multikonferenz Wirtschaftsinformatik, Essen-Germany, 2004.

[12] G. Jorge, M. Ruiz and J. Michael, "The Impact of E-Learning in Medical Education,” in Academic Medicine, 2006.

[13] agelesslearner, "e-Learning- Introductions," 2006. [Online]. Available: http://agelesslearner.com/intros/elearning.ht ml. [Accessed 149 2015].

[14] M.-L. Hung and ,. C. Chou, “"Students' perceptions of instructors' roles in blended and online learning environments: A comparative study," Comput. Educ, vol. 81, pp. 315-325, 2015.

[15] Y. M. Cheng, "Antecedents and consequences of e-learning acceptance," Inf. Syst. J, vol. 21, pp. 269-299, 2011.

[16] J. L. Chen, "The effects of education compatibility and technological expectancy on e-learning acceptance," Comput. Educ, vol. 57, no. 2, pp. 1501-1511, 2011.

[17] T. Dixit and D. Gill, "Developing web based model (disblogwik) in informal eLearning," eLearning.International Journal of Computer Science and Mobile Computing, vol. 2, no. 6, pp. 78-81, 2004.

[18] H. Drachsler, H. Hummel and R. Koper, "Identifying the goal, user model and conditions of recommender systems for formal and informal learning," .Journal of Digital Information, vol. 10, no. 2, pp. 424, 2009.

[19] ,. O. Lassila, "Web Metadata: A Matter of Semantics.," IEEE Internet Computing, vol. 2, no. 4, pp. 30-37, 1998.

[20] S. R. Linta, M. M. Islam and M. R. Islam, "An Enhanced Model of E-Learning Management System Using Semantic Web Technology and Development of Universal Namespace for University Domain,” IJCSI International Journal of Computer Science Issues,, vol. 9, no. 2, 2012.

[21] G. Shrivastav, K. Sharma and A. Bawankan, "A new framework semantic web technology based e-learning," in In Environment and Electrical Engineerin(EEEIC), 2012.

[22] LTSC, "Ieee standard for learning object metadata Technical report,” IEEE, 2002.

[23] S. Shishehchi, S. Banihashem and N. Zin, "Review of personalized recommendation techniques for learne in e-learning systems," in Proceedings Proceedings of the 2011 International Conference on Semantic Technology and Information Retrieval (STAIR, Putrajaya:, 2011. 
[24] P. M. Achar, "Creating an Advanced Web Based Environment Using Semantic Web," International Journal of Management, Technology, and Social Sciences (IJMTS), vol. 2, no. 1, 2017.

[25] G. Ross, “An introduction to Tim BernersLee's Semantic,” 31 January 2005. [Online].

Available:http://www.techrepublic.com/arti cle/an-introduction-to-tim-berners-leessemantic-web/5552998. [Accessed 14 2013].

[26] T. Berners-Lee, "Semantic Web Road map,” 1998. [Online]. Available: http://www.w3.o rg/DesignIssues/Semantic.html..

[27] T. Berners-Lee, J. Hendler and O. Lassila, "The Semantic Web: A new form of Web content that ismeaningful to computers will unleash a revolution of new possibilities.," Scientific American., 2001.

[28] B. Ö. Czerkawski, "THE SEMANTIC WEB IN TEACHER EDUCATION," TOJET: The Turkish Online Journal of Educational Technology, vol. 13, no. 4, October 2014.

[29] P. P. I. Horrocks, "Three Theses of Representation in the Semantic Web,", in Proceedings of the 12th international conference on World Wide Web,, 2003.

[30] L. Yu., Introduction to the Semantic Web and Semantic Web Services, Taylor \& Francis Group, LLC, 2007.

[31] “Semantic_Web," 2018. [Online]. Available:

http://en.wikipedia.org/wiki/Semantic_Web . [Accessed 2013].

[32] M. E. Jianu and A. Vasilateanu, "Designing of an e-learning system using adaptivity and gamification,” in 2017 IEEE International Systems Engineering Symposium (ISSE), Vienna, Austria, 2017.

[33] M.-B. T, Everything Integrated: A Framework for Associative Writing in the Web, University of Southampton, 2004.
[34] A. B. A. J. v. d. M. A. Gerber, "Functional Semantic Web Architecture,", Springer Berlin / Heidelberg, Lecture Notes in Computer Science, Vols. Volume 5021/2008, ISBN:978-3-540-68233-2, pp. pages: 273-287, 2008.

[35] L. O. K. T. S. Michael Daconta, The Semantic web: the guide to future of XML,web services and knowledge management, 2016.

[36]T. David and W. Johanna, "Web semantics and ontology ISBN: 1-59140-905-5," Idea Group, 2006.

[37] A. Fabian , I. I. Bittencourt and E. Costa, "Recommendations in Online Discussion Forums for E-Learning Systems," IEEE Transactions on Learning Technologies, vol. 3, no. 2, pp. 165 - 176, 2010.

[38] H. Drachsler, H. Hummel, and B. den Berg, "Recommendation Strategies for ELearning:Preliminary Effects of a Personal Recommender System for Lifelong Learners," 2017.

[39] V. A. Silvana and I. A. Gabriela , "User Recommender System Based on Knowledge, Availability, and Reputation From Interactions in Forums," IEEE Revista Iberoamericana de Tecnologias del Aprendizaje, vol. 11, no. 1, pp. 18 - 22, 2016.

[40] F. Isinkaye, Y. Folajimi and B. Ojokoh, "Recommendation systems: Principles, methods and evaluation," Egyptian Informatics Journal, vol. 16, p. 261-273, 2015.

[41] H. Knublauch, D. Oberle and P. Tetlow, “A Semantic Web Primer for Object-Oriented Software Developers,” W3C, 2017. [Online].

[42] Y. Tzitzikas and D. Kotzinos, "(Semantic Web) evolution through change logs: Problems and solutions.," in Proceedings of the IASTED International Conference on Artificial Intelligence and Applications, 2017. 
[43] B. Yevgen, B. Hamidreza, B. Igor and F. Michael, "An adjustable personalization of search and delivery of learning objects to learners," Expert Systems with Applications , 2009.

[44] K. Igor, L. Natalya and M. Sergiy, "Personalized Distance Learning Based on Multiagent Ontological System," in Proceedings of the IEEE International Conference on Advanced Learning Technologies, 2004.

[45] Z. Hui, S. Yu and S. Han-tao, "Construction of Ontology-Based User Model for Web Personalization," UM 2007, LNAI 4511, pp. 67-76, 2007.

[46] G. Susan, S. Mirco and P. Alexander., "Ontology-Based User Profiles for Personalized Search,,” DOI10.1007/978-0387-37022-4, Springer US., 2007.

[47] N. Noy and D. McGuinness, "Ontology development 101: A guide to creating your first ontology,"Knowledge Systems Laboratory,Stanford University, 2001.

[48] R. Bansal and S. Chawla, "An approach for semantic information retrieval from ontology in computer science domain," Perspectives in Science, vol. 8, pp. 330333, sep 2016.

[49] L. Stojanovic, S. Staab and R. Studer, "eLearning based on the Semantic Web," in WebNet'2001 World Conference of the WWW and Internet. AACE (2001), 2001.

[50] Djankov, “Trading on time," The Review of Economics and Statistics, pp. 166-173., 2010.

[51] C. U. Yann Duval, "Behind the border trade facilitation in Asia-Pacific: cost of trade, credit information, contract enforcement and regulatory coherence," ARTNeT Working Paper Series, , 2010.

[52] D. Hummels and G. Schaur, "Time as a Trade Barrier," American Economic Review, vol. 103, no. 7, pp. 2935-2959, 2013.
C. Morini, "The impacts of trade facilitation measures on international trade flows.," Policy Research working paper; no. WPS 7367. Washington, D.C. : World Bank Group., Washington, D.C, 2015.

[54] A. BEHAR, P. MANNERS and B. NELSON, "Exports and International Logistics," World Bank Policy Research Working Paper 5691, 2011.

[55] E. T. Moïsé, Orliac and P. Minor , "OECD Trade," OECD Trade Policy Working Papers, 2011.

[56] O. T. F. Indicators, Implementation of the WTO Trade Facilitation Agreement: The Potential Impact on Trade Costs, 2015.

[57] UN/CEFACT, "UN/CEFACT Recommendation No. 33 (2005) Guide published by the UN Centre for Trade Facilitation and Electronic Business," UN/CEFACT, Geneva, 2005.

[58] “Semantic_Web,” 2013. [Online]. Available:

http://en.wikipedia.org/wiki/Semantic_Web . [Accessed 2013].

[59] L. O. K. T. S. Michael Daconta, The Semantic web: the guide to future of XML,web services and knowledge management.

[60] OECD, Implementation of the WTO Trade Facilitation Agreement: The Potential Impact on Trade Costs, 2015.

[61] S. Oufa, M. Abd Ellatif and S. Yehia Helmy, "A proposed paradigm for smart learning environment based on semantic web," Computers in Human Behavior, vol. 27, pp. 796-818, 2017.

[53] d. S. Porto, C. Paulo, Canuto, Otaviano and 